\title{
ESTIMATION OF ABOVE GROUND FOREST BIOMASS USING ULTRA HIGH RESOLUTION UAV IMAGES: A CASE STUDY FROM BARANDABHAR FOREST, NEPAL
}

\author{
U. S. Panday ${ }^{1, *}$, N. Shrestha ${ }^{1}$, S. Maharjan ${ }^{1,2}$ \\ ${ }^{1}$ Department of Geomatics Engineering, School of Engineering, Kathmandu University, Nepal - (uspanday, \\ nawa.shrestha)@ku.edu.np \\ ${ }^{2}$ International Maize and Wheat Improvement Center (CIMMYT), Nepal - maharjan.shashish@gmail.com
}

Commission V, WG V/7 \& Commission IV, WG IV/6

KEY WORDS: Forest Biomass, UAV, Image Segmentation, Visible-NIR Sensor

\begin{abstract}
:
Forest biomass is the sum of above ground living organic material contained in trees which is expressed as dry weight per unit area. Forest biomass acts as substantial terrestrial carbon sinks, they are estimated to absorb 2.7 Petagrams of carbon per year, as such accurate estimation of forest carbon stock is very important. The estimation of biomass is also important because of its application in commercial exploitation as well as in global carbon cycle. Particularly in the latter context, the estimation of the total above-ground biomass (TAGB) with sufficient accuracy is vital in reporting the spatial and temporal state of forest under the United Nations Framework Convention on Climate Change (UNFCCC), Reducing Emissions from Deforestation in Developing Countries (REDD). In this research, tree height, DBH and crown cover were measured using field instruments. Individual ultra-high-resolution UAV images acquired using customized Visible-NIR, were georeferenced and tree crown were extracted using multi-resolution segmentation. A regression equation between field measured biomass and Crown Projection Area (CPA) was developed. The paper presents results from Barandabhar Forest of Chitwan District, Nepal. RMSE of ortho-mosaic was found to be $18 \mathrm{~cm}$. While $\mathrm{R}^{2}$ value of $89 \%$ was obtained for relationship between DBH and biomass, that of $61 \%$ was attained for relationship between CPA and biomass.
\end{abstract}

\section{INTRODUCTION}

Forest biomass is the sum of above ground living organic material contained in trees which is expressed as dry weight per unit area. Forest biomass acts as substantial terrestrial carbon sinks, they are estimated to absorb 2.7 Petagrams of carbon per year $(\mathrm{PgC} \cdot \mathrm{yr}-1)$, as such accurate estimation of forest carbon stock is important. The estimation of biomass is also important because of its application in commercial exploitation as well as in global carbon cycle. Particularly in the latter context, the estimation of total above-ground biomass (TAGB) with sufficient accuracy is vital in reporting spatial and temporal state of forest under the United Nations Framework Convention on Climate Change (UNFCCC), Reducing Emissions from Deforestation in Developing Countries (REDD) (UNFCCC, 2008).

Carbon stock is typically derived from above-ground biomass by assuming that $50 \%$ of the biomass is made up by carbon constituents. Various methods are available to estimate carbon stock of forest. The most accurate method is to use the destructive method; which involves cutting of trees, drying and weighing of their parts. This destructive method is often used to validate others, less invasive and costly methods, such as the estimation of carbon stock using non-destructive in-situ measurements and remote sensing (Clark et al., 2001; Wang, Hall, Scatena, Fetcher, $\mathrm{Wu}, 2003)$. Allometric equations developed on the basis of sparse measurements from destructive sampling are related to more easily collected biophysical properties of trees, such as diameter at breast height $(\mathrm{DBH})$ and commercial bole height $(\mathrm{CBH})$. The estimation of carbon over large areas using remote sensing is supported by correlating the reflection of canopy recorded at the sensor to the carbon measured directly or estimated indirectly on the ground (Chiesi et al., 2005; Gibbs, Brown, Niles, Foley, 2007; Myeong, Nowak, Duggin, 2006; Tan, Piao, Peng, Fang, 2007). Various studies have evaluated the approaches to estimate biomass with the help of remote sensing. Remote sensing offers a potential solution to greater global consistency of estimates. Although biomass carbon (hereafter referred to as biomass) estimates derived from remote sensing may be less accurate at the plot scale than field (ground) measurements, remote sensing is technically capable of spatially continuous biomass estimates over the entire globe at some set level of spatial detail. Thus, it has the potential to eliminate inconsistencies due to differences in measurement programs between diverse countries or agencies. It could eliminate the need for sampling and extrapolation, which has been shown to constitute as much as $98 \%$ of total biomass estimation error. Most of the studies have used Radio Detection And Ranging (RADAR) (e.g., (Li et al., 2007; Sun et al., 2011; Tanase et al., 2014)), Light Detection And Ranging (LiDAR) (e.g. (Hudak et al., 2012; Vaglio Laurin et al., 2014)) and optical multi and hyperspectral data (e.g., (Morel, Fisher, Malhi, 2012; Vaglio Laurin et al., 2014)) in various forest ecosystem. These studies relate field-measured biomass values to train statistical or machine-learning methods in predicting biomass by remote sensing predictors, and the majority report favourably on the accuracy of their biomass predictions.

The wall-to-wall estimation of forest biomass over large areas by ground-based measurements requires a dense network of inventory plots to reach good accuracies. In many regions, this is infeasible due to high costs, required man power and inaccessible field situations. This limitation is particularly evident in many sparsely populated areas with notable portion of natural forest ecosystems that are considered crucial for climate and biodiversity. Satellite images on other hand provides estimates

\footnotetext{
* Corresponding author
} 
over large area with reasonable accuracy, however, it is affected by the presence of shadow and clouds. Unmanned Aerial Vehicle (UAV) uses airborne platform and provides large scale forest measurement that can be used to estimate and validate the product derived from satellites.

The study focuses on the applicability of UAV to estimate and validate the forest biomass. Tree biomass allometric equations are developed by establishing relationship between tree parameters such as CPA, DBH and wood density with aboveground biomass.

\section{METHODOLOGY}

Allometry, relates easily measured variable such as tree diameter, height to other structural and functional characteristics (Niklas, 1994). It is the most common and reliable method for estimating biomass, net primary production, and biogeochemical budgets in forest ecosystems (Gower, Kucharik, Norman, 1999). Practically, most allometry employs diameter at breast height (DBH) as the only independent variable, and develops an allometric relationship between DBH and component biomass (Gower et al., 1999). Some studies proposed to include tree height $(\mathrm{H})$ as the second predictor and develop DBH-H combined equation to improve the precision of biomass estimates e.g. (Ketterings, Coe, Van Noordwijk, Ambagau, Palm, 2001). In general, allometric equations for a tree species are developed using destructive sampling methods. The independent variables, such as diameter at breast height (DBH; $1.37 \mathrm{~m}$ above the ground), are measured for a representative sample (usually over a range of diameters or ages) of trees of a species. These trees are then felled and separated into different components including the main stem (trunk), stem bark, branches and foliage. The fresh weight of each component is measured. Since the intent is to determine dry biomass, the components are then dried in oven (throughout this article tree weight or biomass refers to the above-ground dry biomass).

However, some recent studies have outlined more statistically sound methods for using the sum of components for estimating total biomass. In either case, component or total weights are related to DBH using regression techniques. Since the variation of tree weight is heteroscedastic, that is to say the variation increases with increasing diameter, the use of simple linear regression becomes complicated. Traditionally, this problem is circumvented by taking the logarithm such that

$$
\log M=\log a+b \log D
$$

\subsection{Study Area}

Barandabhar Forest is located in Chitwan district of Nepal. The forest covers an area of $87.9 \mathrm{~km}^{2}$. Barandabhar, a $29 \mathrm{~km}$ long forest patch, is bisected by Mahendra Highway, resulting in a $56.9 \mathrm{~km}^{2}$ area in the buffer zone of Chitwan Nation Park and $31 \mathrm{~km}^{2}$ under District Forest Office, Chitwan. The buffer zone area of Barandabhar Corridor Forest holds $48.016 \mathrm{~km}^{2}$ forest, $5.018 \mathrm{~km}^{2}$ grassland, $3.276 \mathrm{~km}^{2}$ shrub lands and $0.5 \mathrm{~km}^{2}$ of water bodies.

Barandabhar hosts Tropical forest types of Nepal, covering elevation ranges from $150 \mathrm{~m}$ to $400 \mathrm{~m}$. The climate is subtropical dominated by the southeast monsoon. The average annual rainfall is about $250 \mathrm{~cm}$, with most occurring from June through September. From October through February, the weather is dry and cool with average temperatures of $25^{\circ} \mathrm{C}$. From March to June, the weather is hot and temperature can reach as high as $43^{\circ} \mathrm{C}$. The flora of Barandabhar forest is dominated mainly by Sal forest and partly by riverine, tall grassland and short grassland. A sample plot of $0.41 \mathrm{~km}^{2}$ (41 hectare) was used as test site near then
Padampur (New) VDC. The selected area falls under District Forest Office, Chitwan as protected forest area. The location map of the project site is shown in Figure 1.

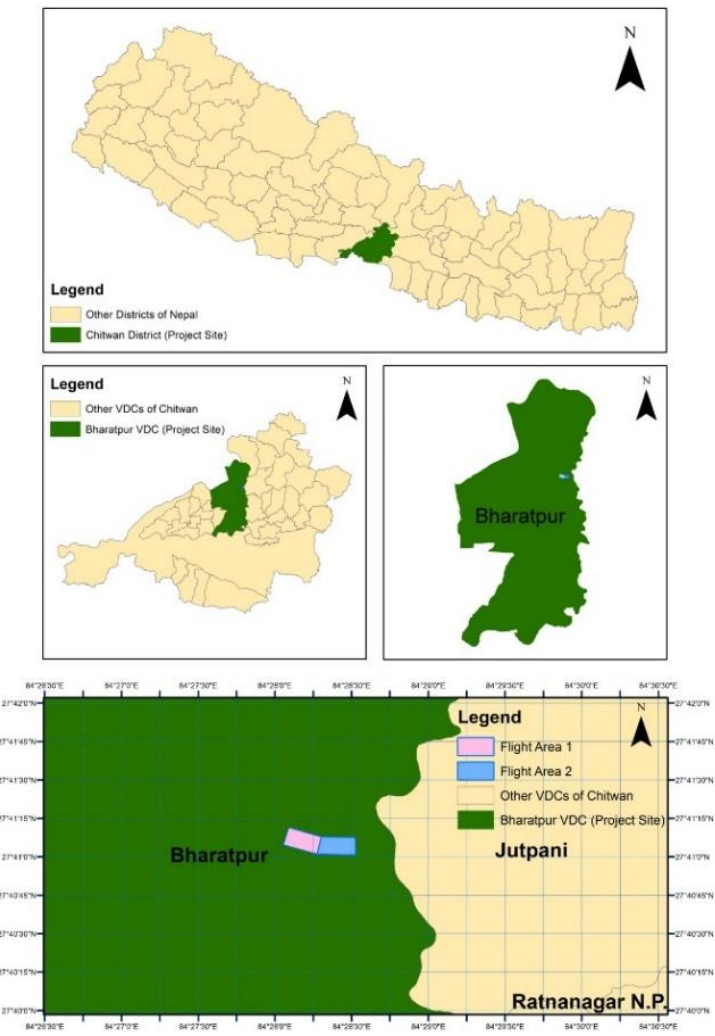

Figure 1. Location map of study area

\subsection{Data Collection}

During the field visit, data pertaining to tree allometry and forest cover were collected. Allometric data such as tree height, DBH and crown cover were measured using field instruments. Similarly, UAV was used to collect the images for the study site. The overall approach is shown in Figure 2.

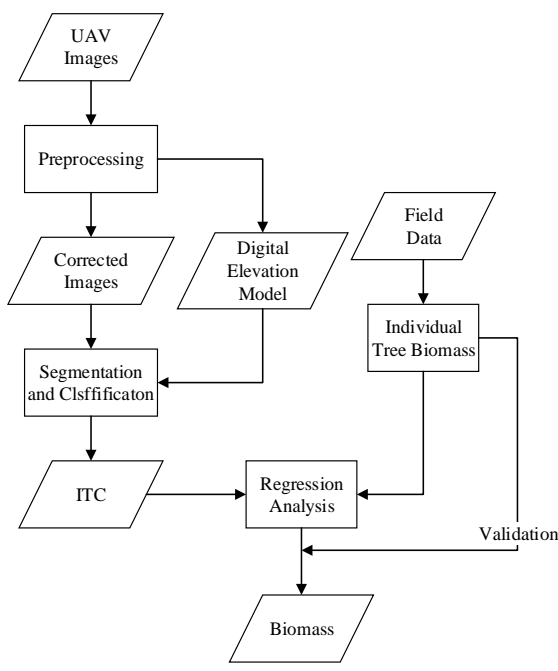

Figure 2. Methodological workflow 


\subsubsection{Allometric Data Collection}

After analysing the density of trees in the area, circular sample plots of $500 \mathrm{~m}^{2}$ were chosen to collect the data. So, a total of 11 plots were studied (Figure 3). The sample plots were navigated using GPS device. DBH and tree height were measured using DBH tape and Vertex instrument respectively. Field plot layout with orientation of trees relative to the North was recorded for identification of trees in image. Besides trees measurement in plots, few individual trees at random were selected and measured for validation purpose. Crown diameter was measured using 4 radii approach along different angular segments of the canopy (Figure 4). These angular segments are orthogonal diameter measurements (4 radii) suitable for computing crown diameter (Hemery, Savill, Pryor, 2005), from which crown projection area can be subsequently derived. The field orientation and extent data were used to interpret and digitize the crown area using visual image interpretation technique. The digitized data were then used for accuracy assessment of the delineated individual tree crowns from UAV image.

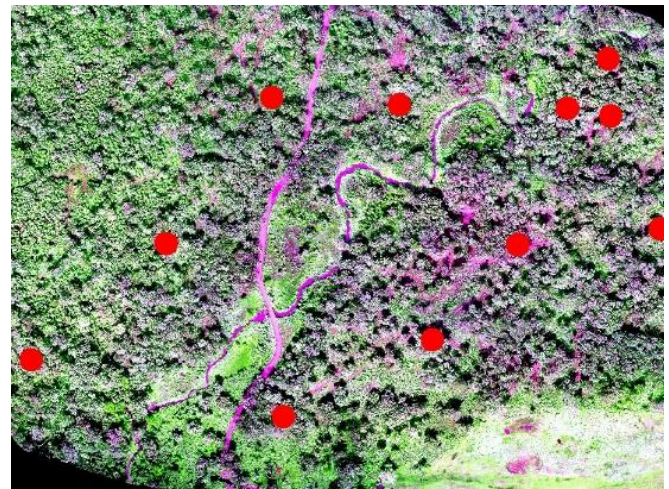

Figure 3. Sample plot distribution (shown in red colour circle)

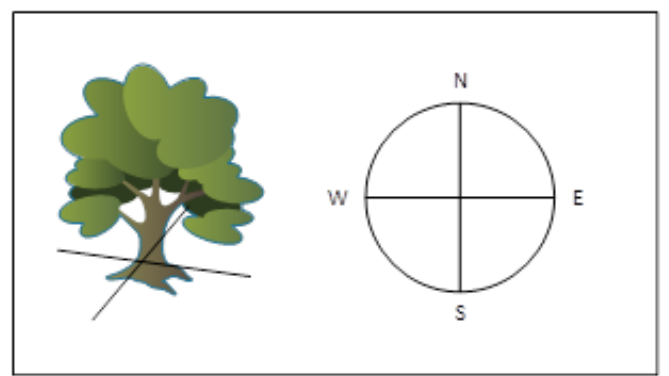

Figure 4. Four-radii approach for crown extent measurement

\subsubsection{UAV Image Acquisition and Georeferencing}

Ground Control Points (GCPs) were placed and measured before conducting aerial survey of the area. One meter by one-meter Red colour cloths were placed as GCP marker. Centre of the cloth was marked and 3D coordinates were recorded in WGS 84 coordinate system. The measurement was done with Differential Global Positioning System (DGPS) in static mode. Post processing of DGPS data was done in GeoMax Geo Office 3.21. A total of 27 GCPs were established and measured, 12 of which were used for geo-referencing while rest were utilized as check points for quality assessment.

UAV images were acquired with xniteSonyA6000NDVI camera (LDP LLC, 2019). The camera's NIR filter was removed and blue blocking filter was inserted. Therefore, it stores Red + NIR in Red channel, Green + NIR in Green channel and NIR in Blue channel. Red and Green channel information was computed and corrected using Python script. Captured images were georeferenced with Agisoft PhotoScan.

\subsection{Biomass Estimation}

\subsubsection{Field Based Estimation}

Biomass of individual trees were calculated based on the field measurement. Individual tree height, DBH and wood density of the Sal (Shorea Robusta) species were used to calculate the biomass. The empirical formula as derived by (Chave et al., 2005) was used for biomass calculation. The equation used is:

$$
\mathrm{AGB}=0.0509 \times \rho \times(\mathrm{DBH})^{2} \times \mathrm{H}
$$

\subsubsection{UAV Based Estimation}

The georeferenced mosaic image was segmented and classified to extract individual tree crown (ITC) cover and regressed with field-based measurement for biomass estimation at plot and forest level.

The first step was to segment the ortho-mosaiced image. It was carried out to separate individual tree crown cover. Segmentation was carried out in series of steps iteratively. Contrast split segmentation followed by multi-resolution segmentation was performed at different hierarchical levels in order to separate and delineate crowns of various sizes.

The contrast split segmentation was used for differentiating elevated surface area from ground area. The DSM was segmented into the bright objects (higher elevated objects) and the dark objects (lower elevated objects). The parameters such as the tile size, step size, class name for the bright and dark objects, minimum and maximum threshold were used while segmentation. Figure 5 shows the result of the contrast split segmentation.

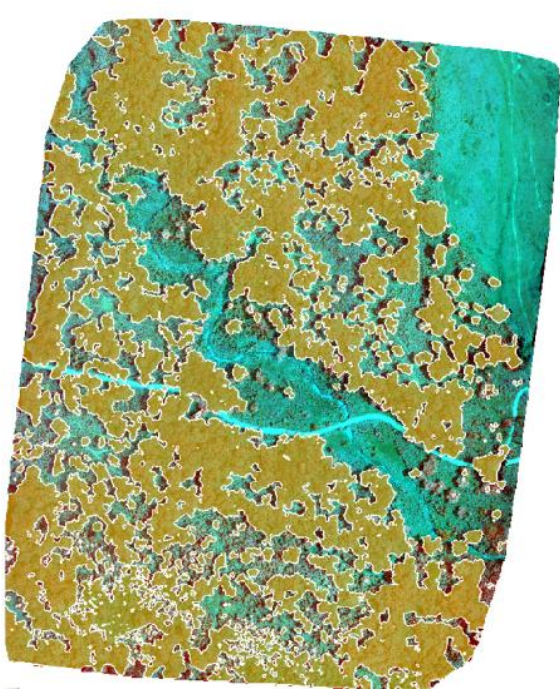

Figure 5. Result of contrast split segmentation

In order to facilitate the appropriate scale for subset of image, ESP tool was used with series of trial and error approach at different scales. The customized algorithm ESP was used in eCognition to get the optimum scale parameters. Individual tree crowns can be delineated as objects through multi-resolution segmentation where the objects are polygons of roughly equal size exhibiting interior homogeneity (Changok, 2007). Most of 
single trees were delineated exactly at larger scale while smaller and connected trees were further segmented at smaller scale.

Hierarchical image segmentation approach helps to delineate tree more efficiently. It is difficult to extract all the trees at the first hit of multi-resolution segmentation. So, taking hierarchical approach into account, those that meet the first criteria are first assigned to one class and then the remaining ones are again subjected to re-segmentation using different parameters in an iterative way. Finally, the same multi-resolution segmentation algorithm is repeated with identical procedure but with different scale parameters until all of the tree crowns are delineated. Figure 6 demonstrates ITC delineation process.

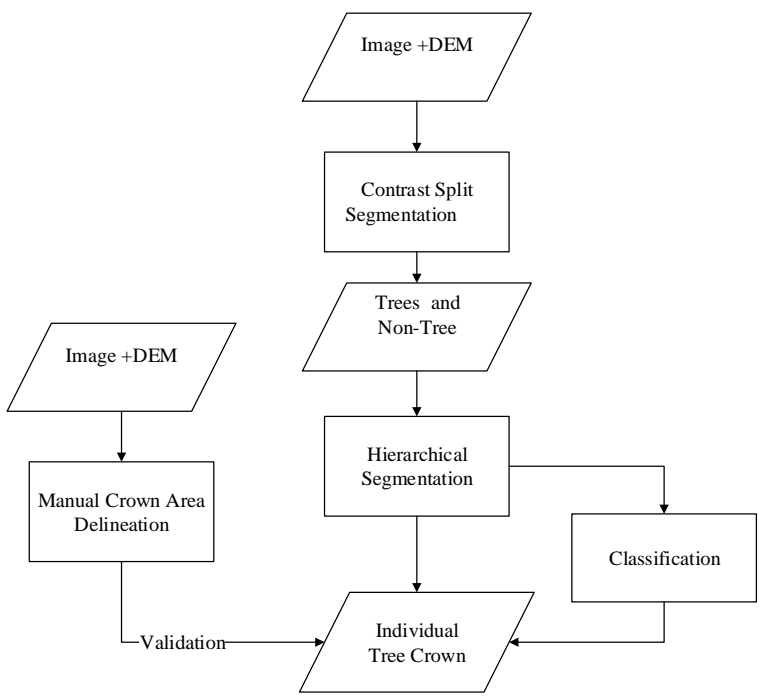

Figure 6. Segmentation and ITC Classification Workflow

The identified trees' crowns were then related with individual trees collected during field enumeration. The matched trees in field and ITC from images were used to derive an allometric equation. Various parameters such as $\mathrm{DBH}$, tree height, crown area, and biomass were plotted and regressed to determine significant relation.

\subsection{Accuracy Assessment and Model Validation}

The accuracy of the crown area as well as biomass were evaluated using different metrics. Some of the metrics used are as follows:

$$
\begin{gathered}
D_{i j}=\sqrt{\frac{\text { Oversegmentation }_{i j}^{2}+\text { Undersegmentation }_{i j}^{2}}{2}} \\
\text { Oversegmentation }_{i j}=1-\frac{\operatorname{area}\left(x_{i} \cap y_{i}\right)}{\operatorname{Area}\left(X_{i}\right)}, y_{i} \in Y_{i}^{*} \\
\text { Undersegmentation }_{i j}=1-\frac{\operatorname{area}\left(x_{i} \cap y_{i}\right)}{\operatorname{Area}\left(Y_{i}\right)}, y_{i} \in Y_{i}^{*}
\end{gathered}
$$

OverSegmentation and UnderSegmentation are in $[0,1]$, where OverSegmentation $=0$ and UnderSegmentation $=0$ define $\mathrm{a}$ perfect segmentation, where the segments match the training objects exactly.

Similarly, performance of the regression was evaluated by measuring the deviation of the estimated versus measured total AGB. The mean across all sites was called average deviation (in $\%)$, and the standard deviation of Error across sites was the standard error (also expressed in \%), and represented the overall predictive power of the regression (Chave et al., 2005).

$$
\bar{S}(\%)=\frac{100}{n} \sum_{i=1}^{n}\left|\frac{\widehat{Y}_{l}-Y_{i}}{Y_{i}}\right|
$$

Where $\bar{S}$ is the average deviation, $Y_{i}=$ the observed biomass, $\widehat{Y}_{l}=$ the estimated biomass, $\mathrm{n}=$ number of observations

The deviation was calculated after the prediction was backtransformed to the unit values and corrected using a correction factor (CF). The log-transformation of the data entails a bias in the final biomass estimation (Baskerville, 1972; Duan, 1983; Parresol, 1999), and uncorrected biomass estimates are theoretically expected to underestimate the real value. A simple, first order, correction for this effect consists of multiplying the estimate by the CF:

$$
C F=\exp \left(\frac{R S E^{2}}{2}\right)
$$

Which is always a number greater than 1 , and where, here again, RSE is obtained from the model regression procedure. The larger RSE is, the poorer the regression model, and the larger the correction factor.

\section{RESULTS AND DISCUSSION}

\subsection{Image Acquisition and Processing}

A custom-made Hexa-copter was used as UAV platform for image acquisition (Figure 7). Its specification is presented in Table 1. Flight plan was prepared using DJI Ground Control Station software. An NDVI camera (xniteSonyA6000NDVI) from LDP LLC (LDP LLC, 2019) was used (Table 2). The images were acquired from $200 \mathrm{~m}$ elevation with forward and side lap of $70 \%$ and $50 \%$ respectively. Root mean square error (RMSE) of ortho-mosaic obtained was found to be $18 \mathrm{~cm}$ in planimetric and $46 \mathrm{~cm}$ in vertical direction.

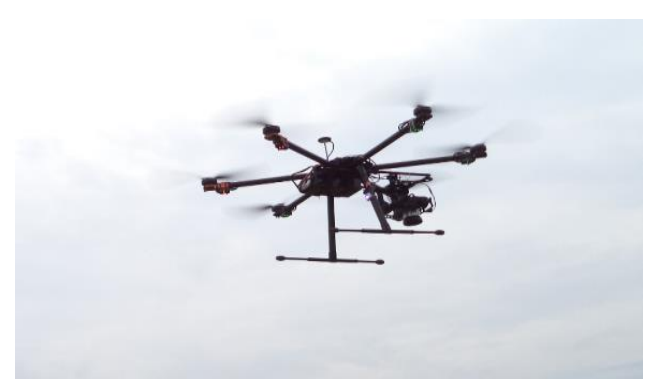

Figure 7. Hexa-copter used for image capture

\begin{tabular}{|l|l|}
\hline Parameter & Value \\
\hline Dimension (motor to motor) & $960 \mathrm{~mm}$ \\
$\begin{array}{l}\text { Self-weight (including } \\
\text { camera gimbal) }\end{array}$ & $6.5 \mathrm{~kg}$ \\
Suggested payload & $1.5-2 \mathrm{~kg}$ \\
Maximum thrust & $20 \mathrm{~kg}$ \\
Propeller size and pitch & $18 \mathrm{inch} / 6.1$ \\
Flight control board & Wokoong-M (50 waypoints) \\
\hline
\end{tabular}




\begin{tabular}{|l|l|}
\hline Flight time & Approx. 20 min \\
Flight mode & $\begin{array}{l}\text { Manual \& Waypoint } \\
\text { navigation }\end{array}$ \\
Maximum horizontal speed & $25 \mathrm{~m} / \mathrm{s}$ \\
Maximum vertical speed & $5 \mathrm{~m} / \mathrm{s}$ \\
\hline
\end{tabular}

Table 1. Specification of Hexa-copter

\begin{tabular}{|l|l|}
\hline Parameter & Value \\
\hline Camera Model & xniteSonyA6000NDVI \\
Bands recorded & R-G-NIR \\
Focal Length $(\mathrm{mm})$ & 30 \\
Sensor width $(\mathrm{mm})$ & 23.5 \\
Sensor height $(\mathrm{mm})$ & 15.6 \\
Image size used (pixel $\times$ pixel) & $4240 \times 2400$ \\
Sensor width $(\mathrm{mm})$ & 23.5 \\
Sensor height $(\mathrm{mm})$ & 15.6 \\
\hline
\end{tabular}

Table 2. Camera specification

\subsection{Crown Area Delineation}

The comparison between the segmented individual tree crown (ITC) and digitized ITC were analysed using approach described in method section. The $\mathrm{D}$ value was 0.32 while over segmentation was 0.42 and under segmentation was 0.18 . The lower $\mathrm{D}$ value can be result of various factors that governs the quality of the images. Resampling of image pixels from original image during image mosaicking and ortho-rectification results errors leading to poor quality of images. The error during the process leads in improper matching of the crown area especially in forested areas due to mismatching of points in overlapping areas.

Likewise, the error in individual tree crown delineation can also be attributed to sensor characteristics of consumer grade modified cameras. Consumer grade cameras have limited dynamic range $\mathrm{CCD} / \mathrm{CMOS}$ sensors that forces the use of camera auto-exposure and prevents conversion of digital numbers into calibrated radiance values. In complex scenes, local differences in direct versus diffuse illumination may further obscure the changes of interest. Furthermore, consumer cameras apply nonlinear transformations to the image data in ways that are beyond user control (Wüller, Gabele, 2007). It is therefore not possible to effectively correct for the changes in illumination and exposure.

Similarly, sensors in consumer-grades cameras are optimized for true-colour RGB recording, which negatively influences the separability of the three channels after infrared conversion. The band configuration is determined by additive rejection of the Bayer filter array and the installed long pass filter. This results in considerable overlap in sensitivity among the channels and prevents separate recording of red and infrared light. As a result, the bands are highly collinear.

\subsection{Descriptive Statistics}

Out of the 95 trees sampled in the field, most of the trees have diameter at breast height of $50-60 \mathrm{~cm}$ showing matured trees in the study area. The DBH ranges from as small as $10-20 \mathrm{~cm}$ to $80-$ $90 \mathrm{~cm}$ while the mean DBH lies in 50-60 cm (Figure 8).

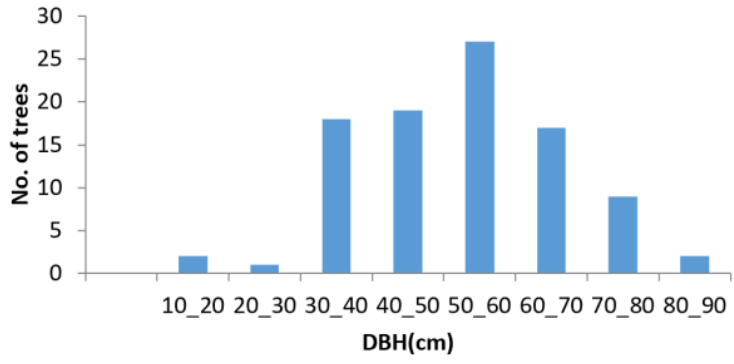

Figure 8. Number of trees under different DBH classes

The number of trees were categorized under different classes according to their height. The maximum number of trees (i.e. 43) falls in height class of $20-30 \mathrm{~m}$ and the least number of trees (i.e. 2) falls in height class of 40-50m (Figure 9).

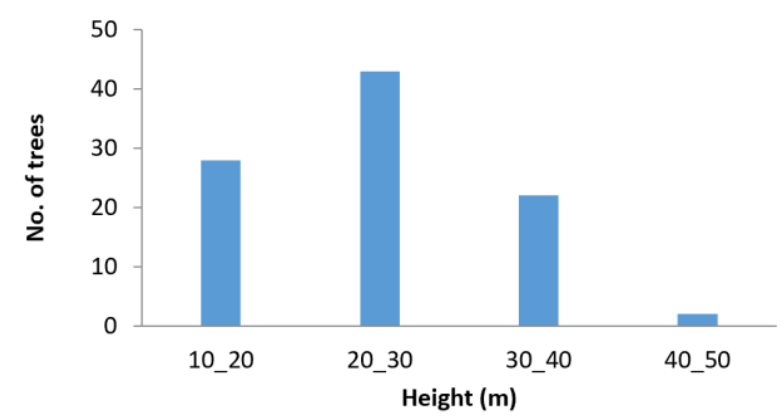

Figure 9. Number of trees according to tree height

Similarly, trees were categorized as per crown area. The study area was largely dominated by trees with crown area of $60-80 \mathrm{~m}^{2}$. while the minimum crown area was between $0-20 \mathrm{~m}^{2}$, the maximum was $180-200 \mathrm{~m}^{2}$ (Figure 10 ). The average value of crown areas of all trees was found to be $74.49 \mathrm{~m}^{2}$.

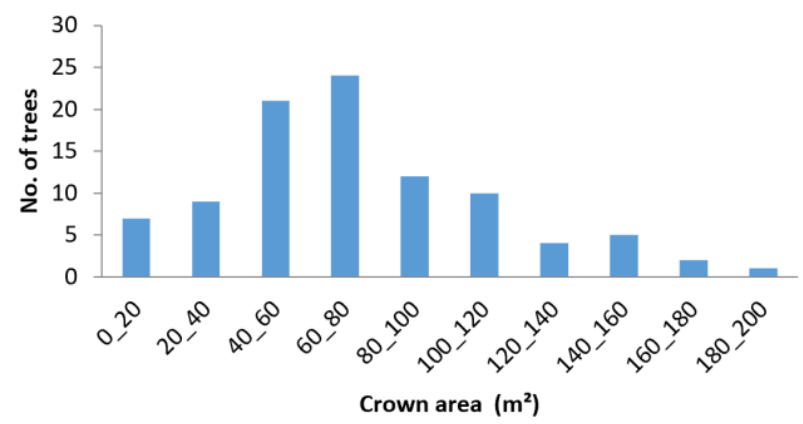

Figure 10. Tree categories as per Crown Area

\subsection{Regression Analysis}

Scatter plots of various variables such as DBH, tree height, crown area and biomass were used to analyse regression curves of the log-transformed models. Logarithmic transformations were used to simplify the regression procedure and satisfy the assumption of homogenous variance as discussed by (Bond-Lamberty, Wang, Gower, 2002).

The regression analysis between DBH and Crown Area shows significant relation, showing coefficient of determination of 0.60 (Figure 11). The lower value of coefficient of determination can 
be attributed to error in field measurement and individual crown delineation. Matured and overlapping trees might be a cause for the less value of the $\mathrm{R}^{2}$ as crowns are difficult to identify in case of overlapping trees. As the study area is dominated by matured trees, tree crowns are subject to various extreme natural phenomena that might shape the crown inappropriately.

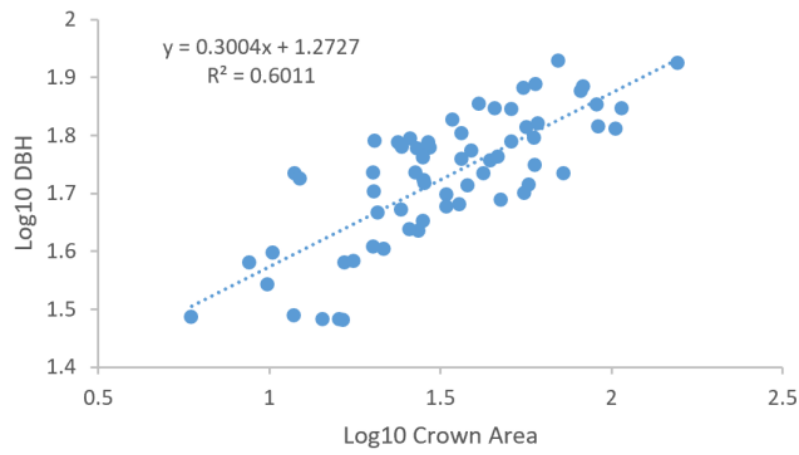

Figure 11. Relationship between DBH and Crown Area

The relationship between DBH and above ground tree biomass (AGTB) shows significant correlation with $\mathrm{R}^{2}$ value of $89 \%$ (Figure 12).

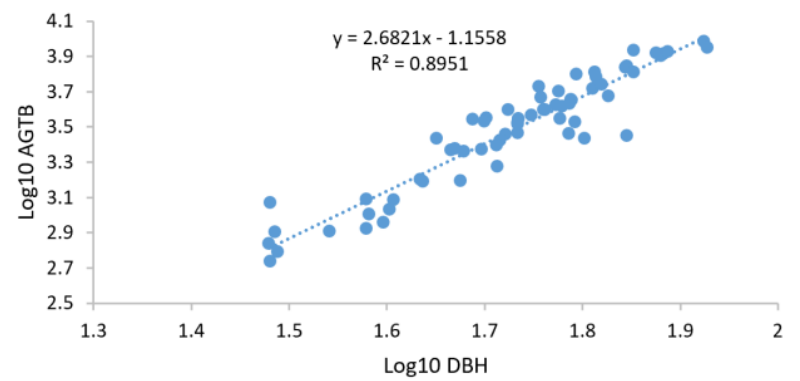

Figure 12. Relationship between DBH and AGTB

Similarly, the plot between the crown area and AGTB shows (Figure 13) that there exists linear relationship between them. The value of coefficient of determination was found to be 0.61 . The lower value of $\mathrm{R}^{2}$ is result of inappropriate crown area delineation from the image. The goodness of fit of our model was measured by comparing the estimated biomass versus the measured biomass. The average deviation was found to be 20.06 and standard error estimate of 0.2963 as per the method discussed in Section 2.4. As the log-transformed data entails a bias in the final biomass estimation (Chave et al., 2005), and uncorrected biomass estimates are theoretically expected to underestimate the real value. A simple, first order, correction factor was calculated to be 1.2011 .

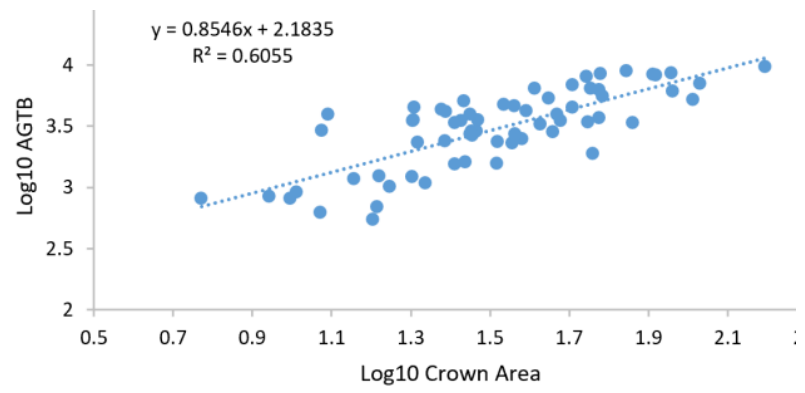

Figure 13. Relationship between Crown Area and AGTB
Errors in measurement of DBH can influence estimates of the allometric coefficients. For example, the ambiguity with which DBH has been defined in the past could be one source (Brokaw, Thompson, 2000). According to (Molto, Rossi, Blanc, 2013) a bias of $\pm 10 \%$ in DBH estimates can result in $\pm 20 \%$ or more bias in biomass estimates.

\section{CONCLUSION AND RECOMMENDATIONS}

UAV based approach is the most feasible method of above ground tree biomass estimation (AGTB), as it facilitates the ground-based measurement with satellite-based measurements. Unlike traditional destructive method, it is environmentalfriendly, cheap and less time-consuming approach. Another benefit of this method is data can be taken periodically. Though satellite remote sensing is highly used in sectors like forestry and agriculture, the approach to estimate AGTB using UAV images is quite new. UAV images can give better result than satellite image as there is no problem of solar angle or shadow effect in UAV images.

The biomass estimates from the Barandabhar Forest shows that the biomass can be predicted with reasonable accuracy. However, precise field measurement of allometric data, spectral responsivity of camera system, ortho-rectification and individual tree crow delineation should be considered as vital in increasing accuracy. Similarly, spectral and spatial responsivity and separability of camera system used to acquire data has to be estimated as well.

The authors recommend that camera spectral and spatial responsivity should be carried out well in advance for finding out the errors associated the imaging system.

\section{ACKNOWLEDGEMENTS}

The project was supported by ICIMOD through Small Scale Application (SSA). The authors thanks ICIMOD for providing us funding to conduct the research. The authors acknowledge Dipesh Suwal, Shangharsha Thapa and Sumesh K.C. for their tireless efforts during the field activities. We are also thankful to Sumesh K.C. for writing Python script for correcting reflectance values recorded by modified consumer camera.

\section{REFERENCES}

Baskerville, G. L., 1972. Use of logarithmic regression in the estimation of plant biomass. Canadian Journal of Forest Research, 2(1), 49-53.

Bond-Lamberty, B., Wang, C., Gower, S. T., 2002. Aboveground and belowground biomass and sapwood area allometric equations for six boreal tree species of northern Manitoba. Canadian Journal of Forest Research. https://doi.org/10.1139/x02-063

Brokaw, N., Thompson, J., 2000. The H for DBH. Forest Ecology and Management. https://doi.org/10.1016/S03781127(99)00141-3

Changok, L., 2007. Estimation of urban tree crown volume based on object-oriented approach and lidar data. University of Twente. Retrieved from https://webapps.itc.utwente.nl/librarywww/papers_2007/msc/gf $\mathrm{m} / \mathrm{lim} . \mathrm{pdf}$

Chave, J., Andalo, C., Brown, S., Cairns, M. A., Chambers, J. Q., Eamus, D., ... Yamakura, T., 2005. Tree allometry and improved 
estimation of carbon stocks and balance in tropical forests. Oecologia. https://doi.org/10.1007/s00442-005-0100-x

Chiesi, M., Maselli, F., Bindi, M., Fibbi, L., Cherubini, P., Arlotta, E., ... Seufert, G., 2005. Modelling carbon budget of Mediterranean forests using ground and remote sensing measurements. Agricultural and Forest Meteorology. https://doi.org/10.1016/j.agrformet.2005.09.011

Clark, D. A., Brown, S., Kicklighter, D. W., Chambers, J. Q., Thomlinson, J. R., Ni, J., Holland, E. A., 2001. Net primary production in tropical forests: An evaluation and synthesis of existing field data. Ecological Applications. https://doi.org/10.1890/1051-

0761(2001)011[0371:NPPITF]2.0.CO;2

Duan, N., 1983. Smearing estimate: A nonparametric retransformation method. Journal of the American Statistical Association. https://doi.org/10.1080/01621459.1983.10478017

Gibbs, H. K., Brown, S., Niles, J. O., Foley, J. A., 2007. Monitoring and estimating tropical forest carbon stocks: Making REDD a reality. Environmental Research Letters. https://doi.org/10.1088/1748-9326/2/4/045023

Gower, S. T., Kucharik, C. J., Norman, J. M., 1999. Direct and indirect estimation of leaf area index, $\mathrm{f}(\mathrm{APAR})$, and net primary production of terrestrial ecosystems. Remote Sensing of Environment. https://doi.org/10.1016/S0034-4257(99)00056-5

Hemery, G. E., Savill, P. S., Pryor, S. N., 2005. Applications of the crown diameter-stem diameter relationship for different species of broadleaved trees. Forest Ecology and Management. https://doi.org/10.1016/j.foreco.2005.05.016

Hudak, A. T., Strand, E. K., Vierling, L. A., Byrne, J. C., Eitel, J. U. H., Martinuzzi, S., Falkowski, M. J., 2012. Quantifying aboveground forest carbon pools and fluxes from repeat LiDAR surveys. Remote Sensing of Environment. https://doi.org/10.1016/j.rse.2012.02.023

Ketterings, Q. M., Coe, R., Van Noordwijk, M., Ambagau', Y., Palm, C. A., 2001. Reducing uncertainty in the use of allometric biomass equations for predicting above-ground tree biomass in mixed secondary forests. Forest Ecology and Management. https://doi.org/10.1016/S0378-1127(00)00460-6

LDP LLC, 2019. Camera Conversions. Retrieved October 1, 2019, from https://maxmax.com/

Li, X., Yeh, A. G. O., Wang, S., Liu, K., Liu, X., Qian, J., Chen, X., 2007. Regression and analytical models for estimating mangrove wetland biomass in South China using Radarsat images. International Journal of Remote Sensing. https://doi.org/10.1080/01431160701227638

Molto, Q., Rossi, V., Blanc, L., 2013. Error propagation in biomass estimation in tropical forests. Methods in Ecology and Evolution. https://doi.org/10.1111/j.2041-210x.2012.00266.x

Morel, A. C., Fisher, J. B., Malhi, Y., 2012. Evaluating the potential to monitor aboveground biomass in forest and oil palm in Sabah, Malaysia, for 2000-2008 with Landsat ETM+ and ALOS-PALSAR. International Journal of Remote Sensing. https://doi.org/10.1080/01431161.2011.631949
Myeong, S., Nowak, D. J., Duggin, M. J., 2006. A temporal analysis of urban forest carbon storage using remote sensing. Remote Sensing of Environment. https://doi.org/10.1016/j.rse.2005.12.001

Niklas, K. J., 1994. Plant Allometry: The Scaling of Form and Process. Chicago, Illinois: University of Chicago Press.

Parresol, B. R., 1999. Assessing tree and stand biomass: A review with examples and critical comparisons. Forest Science. https://doi.org/10.1093/forestscience/45.4.573

Sun, G., Ranson, K. J., Guo, Z., Zhang, Z., Montesano, P., Kimes, D., 2011. Forest biomass mapping from lidar and radar synergies. Remote Sensing of Environment. https://doi.org/10.1016/j.rse.2011.03.021

Tan, K., Piao, S., Peng, C., Fang, J., 2007. Satellite-based estimation of biomass carbon stocks for northeast China's forests between 1982 and 1999. Forest Ecology and Management. https://doi.org/10.1016/j.foreco.2006.12.018

Tanase, M. A., Panciera, R., Lowell, K., Tian, S., Hacker, J. M., Walker, J. P., 2014. Airborne multi-temporal L-band polarimetric SAR data for biomass estimation in semi-arid forests. Remote Sensing of Environment. https://doi.org/10.1016/j.rse.2014.01.024

UNFCCC, 2008. Report of the Conference of the Parties on its thirteenth session, held in Bali from 3 to 15 December 2007. Http://Unfccc.Int/Resource/Docs/2007/Cop13/Eng/06a01.Pdf. https://doi.org/10.1016/j.biocon.2006.08.013

Vaglio Laurin, G., Chen, Q., Lindsell, J. A., Coomes, D. A., Frate, F. Del, Guerriero, L., ... Valentini, R., 2014. Above ground biomass estimation in an African tropical forest with lidar and hyperspectral data. ISPRS Journal of Photogrammetry and Remote Sensing. https://doi.org/10.1016/j.isprsjprs.2014.01.001

Wang, H., Hall, C. A. S., Scatena, F. N., Fetcher, N., Wu, W., 2003. Modeling the spatial and temporal variability in climate and primary productivity across the Luquillo Mountains, Puerto Rico. Forest Ecology and Management. https://doi.org/10.1016/S0378-1127(02)00489-9

Wüller, D., Gabele, H., 2007. The usage of digital cameras as luminance meters. In Digital Photography III. https://doi.org/10.1117/12.703205 